OPEN ACCESS

Edited by:

Amit Baumel,

University of Haifa, Israel

Reviewed by:

Maurice Mars,

University of KwaZulu-Natal,

South Africa

Jeffrey Soar,

University of Southern

Queensland, Australia

${ }^{*}$ Correspondence:

Emnet Getachew

emnet.getachew@aau.edu.et

Specialty section:

This article was submitted to

Human Factors and Digital Health,

a section of the journal

Frontiers in Digital Health

Received: 24 November 2021

Accepted: 03 February 2022

Published: 28 February 2022

Citation:

Getachew E, Woldeamanuel $Y$ and Manyazewal T (2022) Capacity and Readiness Assessment of Healthcare

Facilities for Digital Health Interventions Against Tuberculosis and

HIV in Addis Ababa, Ethiopia.

Front. Digit. Health 4:821390

doi: 10.3389/fdgth.2022.821390

\section{Capacity and Readiness Assessment of Healthcare Facilities for Digital Health Interventions Against Tuberculosis and HIV in Addis Ababa, Ethiopia}

\author{
Emnet Getachew ${ }^{1,2 *}$, Yimtubezinash Woldeamanuel ${ }^{1}$ and Tsegahun Manyazewal $^{1}$ \\ ${ }^{1}$ Center for Innovative Drug Development and Therapeutic Trials for Africa (CDT-Africa), College of Health Sciences, Addis \\ Ababa University, Addis Ababa, Ethiopia, ${ }^{2}$ Department of Public Health, College of Health Science, Arsi University, Asella, \\ Ethiopia
}

Background: There is a high level of concern that low-income countries lack the capacity and readiness to effectively adopt, implement, and scale up digital health interventions (DHIs). We aimed to assess the infrastructure and human resource capacity and readiness of healthcare facilities to adopt and implement any new DHI for tuberculosis (TB) and HIV care and treatment in Addis Ababa, Ethiopia.

Method: We carried out a cross-sectional, mixed-methods study in 14 public healthcare facilities that provide TB and HIV care and treatment services. Providers' perceived readiness to adopt and implement digital health was assessed using a self-administered questionnaire designed based on an adapted eHealth readiness assessment model that covers six domains: core readiness, organizational cultural readiness, value proposition readiness, technological readiness, regulatory policy readiness, and operational resource readiness. The infrastructure and human resource capacity were assessed on-site using a tool adapted from the Technology Infrastructure Checklist. Internal consistency was assessed using Cronbach's alpha, and the significant relationship between the composite variables was assessed using Pearson's correlation coefficients ( $r$ ).

Result: We assessed 14 facilities on-site and surveyed 60TB and HIV healthcare providers. According to Cronbach's alpha test, all the six technology acceptance domains had a value of $>0.8$, suggesting a strong interrelatedness between the measuring items. The correlation between technological readiness and operational resource readiness was significant $(r=0.8)$. The providers perceived their work environment as good enough in electronic data protection, while more efforts are needed in planning, training, adapting, and implementing digital health. Of the 14 facilities, $64.3 \%$ lack the plan to establish a functional local area network, and 43\% lack skilled staff on payroll to provide maintenance of computers and other digital technologies.

Conclusion: Like many developing countries, there was a modest infrastructure and human resource capacity and readiness of public healthcare facilities in Addis Ababa, Ethiopia, to nurture and strengthen DHIs across the TB and HIV cascades of care. 
Technological and operational resource readiness, including funding and a Well-trained workforce, are essential for successful implementation and use of digital health against the two infectious diseases of global importance in such settings.

Keywords: digital health, eHealth, health technology, tuberculosis (TB), human immunodeficiency virus (HIV), Ethiopia

\section{INTRODUCTION}

Digital health interventions (DHIs) are specified as using digital devices, mobile and wireless technologies to support the achievement of health goals (1-3). The World Health Organization (WHO) defines DHI as a discrete functionality of digital technology applied to attain health objectives (4). DHI indicates the general use of necessary information and communication technologies (ICT) for health, consisting of both mobile health (mHealth) and electronic health (eHealth). Various countries have been evaluating the potential uses of DHI to improve treatment adherence, medical records, disease surveillance, program monitoring, treatment follow-up, laboratory management, and eLearning to enhance clinical care, treatment, and disease prevention and control (5-9).

The main challenge to implementing and integrating DHIs into the health system for evidence-based decision-making is the lack of enough information about country-specific digital health capacity and the larger ICT ecosystem (10-13). Understanding how theoretically promised DHIs to work within a specific local context is significant to ascertain context-sensitive DHIs implementation and scale-up. Information about the legal, ethical, and social implications in the adoption of DHIs and where and how such technologies can be deployed have been a major gap in the literature (14-16). Acceptability of such technologies by front-line healthcare providers is one of the indicators of health facility readiness to adopt and implement DHIs. The theoretical basis for this study is that healthcare workers' perspectives and the health facilities' capacity and readiness are critical in determining the extent and success of the implementation of DHIs.

There have been decades of investments made in the prevention and control of tuberculosis (TB) and human immunodeficiency virus (HIV), the two infectious diseases of global importance. Several studies have confirmed that TB and HIV will continue to pose major challenges without the deployment of innovative prevention and treatment strategies for everyone who needs them (17-21). For countries like Ethiopia that are overwhelmed by the dual burden of the two diseases, advancing the diagnosis, care, and treatment programs are essential to meeting global targets such as the 2035 End TB Strategy and the 2030 end AIDS epidemic (22-26). The Use of DHIs could be one of such elements while understanding the current infrastructure, human resources, and health systems potential is critical for their successful deployment and practice.

Thus, this study aimed to assess the infrastructure, and human resource capacity, and readiness of healthcare facilities to adopt and implement any new DHI for tuberculosis (TB) and HIV care and treatment in Addis Ababa, Ethiopia.

\section{METHODS}

A facility-based, mixed-method cross-sectional study was conducted in government-owned hospitals and health centers ( $n$ $=14$ ) in Addis Ababa, Ethiopia. The study used a combination of an interview with a semi-structured, interviewer-administered questionnaire, self-administered questionnaire, and a checklistbased assessment of sites. Data were collected between January and March 2021.

\section{Setting and Participants}

There were 94 health centers in the 10 sub-cities of Addis Ababa, of these, 10 with high TB/HIV patient flow, one from each subcity, were included (Table 1). There were six hospitals led by the city administration, of these, four with high TB/HIV patient flow were included.

The study population was all TB or HIV healthcare providers who were working in the 14 selected healthcare facilities. The study included consented healthcare professionals who were working in TB or HIV clinics at the time of data collection, but excluded those with $<6$ months of work experience as they may have little or ambiguous information about the study site and the subject of interest. The sample size depended on the scope of the study and the possibility of getting eligible participants in each study site; thus guided by the purposive sampling technique. There were 76 healthcare providers working at the selected sites, of whom $60(80 \%)$ met the inclusion criteria and participated.

\section{Data Collection}

The participants responded to a self-administrated, structured, and adopted questionnaire aimed to assess the facilities' capacity and readiness to adopt and implement DHIs. The questionnaire

TABLE 1 | Included public health centers from each sub-city.

\begin{tabular}{lll}
\hline No. & Name of Health Center & Sub-city \\
\hline 1 & Addis Raey Health Center & Addis ketema \\
2 & Akaki Health Center & Akaki kality \\
3 & Kebena Health Center & Arada \\
4 & Goro Health Center & Bole \\
5 & Adisu Gebeya Health Center & Gulele \\
6 & Kazanchis Health Center & Kirkos \\
7 & Alem Bank Health Center & Kolfe \\
8 & Teklehaymanot Health & Lideta \\
9 & Woreda 02 Health Center & Nifasilk lafto \\
10 & Woreda 13 Health Center & Yeka
\end{tabular}




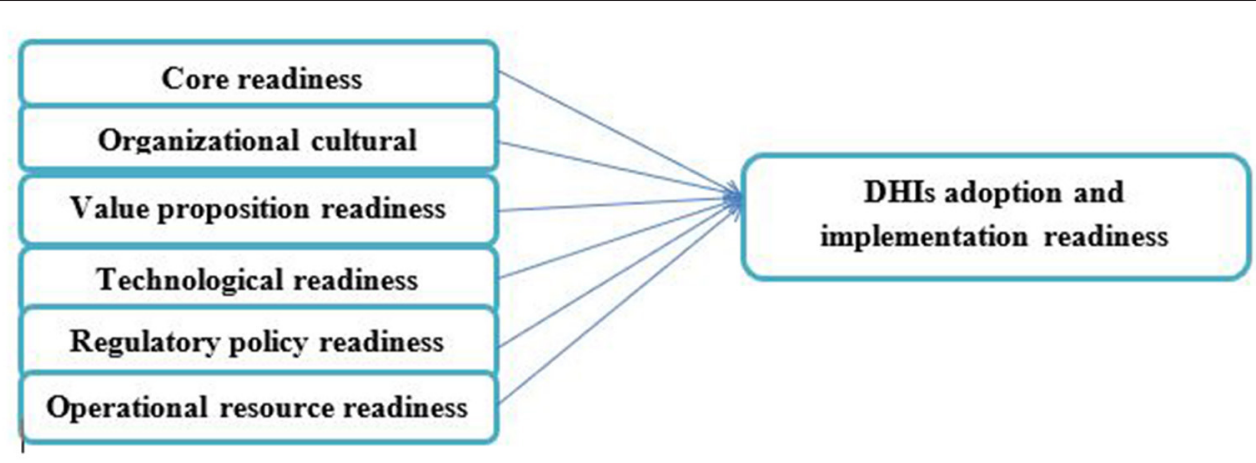

FIGURE 1 | DHls Adoption and Implementation Readiness model (27-29).

was adapted from eHealth readiness assessment models (2729) that cover six domains: core readiness (CR); organizational cultural readiness (OCR); operational resource readiness (ORR); technological readiness (TR); value proposition readiness (VPR); and regulatory and policy readiness (RPR) (Figure 1) (27-29).

The questionnaires were filled out by a person who was entitled to a managerial position in each department, i.e., HIV and TB clinics, to assess facility readiness $(n=28)$. A semistructured interview was also conducted, and the interview was mainly focused on the previous experience of care providers in using different technologies and their overall evaluation of their facilities' readiness to adopt and implement new digital technology in their department $(n=60)$. The healthcare providers usually work in very busy clinics; therefore, nearby unoccupied office spaces were used to ensure participants' privacy and to manage their time effectively. The interview was lasted for about 20 to $30 \mathrm{~min}$ and was conducted in the local language (Amharic) or English depending on the interest of each participant, and it was audio recorded. The audio recording was later transcribed and the Amharic translated to English to produce de-identified English-language transcripts.

A checklist adapted from the Technology Infrastructure Checklist and other sources $(30,31)$ was used to assess the current infrastructure and human resource capacity of the included facilities, with emphasis given to $\mathrm{TB}$ and HIV clinics. The purpose was to understand the gaps and opportunities to adopt new DHIs in those sectors. The checklist was completed by making on-site observations, and if any additional information was needed, facility-level health information managers were consulted.

\section{Data Processing and Management}

Any physical records including informed consent forms and paper-based questionnaires were safeguarded in a locked personal cabinet. Interview records and transcripts were stored on a coded password-protected computer to ensure the confidentiality of participants' data. One-quarter of English language transcripts were randomly chosen and were assessed against the original audio recordings to verify the correctness and completeness of the gathered data.

\section{Data Analysis}

The close-ended questionnaire and the checklist were analyzed quantitatively using SPSS version 20, and most interview questions were analyzed qualitatively using thematic analysis. All readiness assessment variables had a 5 point Likert scale value. Depending on the questions, the responses were dichotomized. The Likert scale questions with potential responses "No never considered," "No but have considered," "Yes in progress," "Yes nearly completed," and Yes in place" were analyzed considering the last three responses supportive that indicate positive values. Similarly, the Likert scale questions with the response "Agree" and "Strongly agree" were aggregated as positive values.

\section{Data Quality Assurance}

The reliability and internal consistency of each factor in the adapted data collection instrument were assessed using Cronbach's Alpha, with the value 0.7 used as the cut-off point. A Pre-test of the study questionnaires was conducted at selected health facilities on $10 \%$ of the estimated sample size. The training was provided to the study data collectors. A Study Supervisor and the Principal Investigator verified the collected data for completeness daily.

\section{Ethical Considerations}

The study protocol has been reviewed and approved by the Scientific and Ethics Review Committee of the Center for Innovative Drug Development and Therapeutic Trials for Africa (CDT-Africa), College of Health Sciences, Addis Ababa University, and the Ethics Review Committee of the Addis Ababa Health bureau. An official letter was sent to each study site for permission to undertake the study accordingly. At the individual level, after a clear explanation of the purpose and importance of the study, written informed consent was obtained from all participants before they participate in the study.

\section{RESULT}

\section{Socio-Demographic Characteristics}

We surveyed $60 \mathrm{~TB}$ and HIV healthcare providers, of whom $60 \%$ were female, $42 \%$ were aged between 31 and 40 years, $65 \%$ held a BSc degree, and $36.7 \%$ had more than 10 years of working 
TABLE 2 | Socio-demographic characteristics.

\begin{tabular}{|c|c|c|}
\hline & No. & $\%$ \\
\hline Total & 60 & 100 \\
\hline \multicolumn{3}{|l|}{ Gender } \\
\hline Male & 24 & 40 \\
\hline Female & 36 & 60 \\
\hline \multicolumn{3}{|l|}{ Age } \\
\hline $18-30$ & 16 & 26.7 \\
\hline $31-40$ & 25 & 41.7 \\
\hline $41-50$ & 15 & 25 \\
\hline Above 51 & 4 & 6.7 \\
\hline \multicolumn{3}{|l|}{ Educational level } \\
\hline College diploma & 10 & 16.7 \\
\hline BSc & 39 & 65 \\
\hline MSc & 11 & 18.3 \\
\hline \multicolumn{3}{|l|}{ Department } \\
\hline TB room & 23 & 38.3 \\
\hline HIV room & 37 & 61.7 \\
\hline \multicolumn{3}{|l|}{ Work experience } \\
\hline$>1$ year & 2 & 3.3 \\
\hline $2-5$ & 16 & 26.7 \\
\hline $6-9$ & 20 & 33.3 \\
\hline Above 10 & 22 & 36.7 \\
\hline
\end{tabular}

experience (Table 2). Departmentally, 62\% were working in HIV clinics.

\section{Technology Utilization}

Eighty percent of the participants have been using DHIs in their respective facilities. Healthcare providers at HIV clinics utilized a smart care system to keep patient data electronically, report data to concerned bodies, and retrieve data. The healthcare providers had been given some training to use such technologies appropriately, while only $26 \%$ were satisfied with the training, replying that the training provided was not enough to use the technology appropriately (Table 3).

According to the data obtained from the respondents, TB care providers in hospitals were less familiar with DHI utilization than those in health centers. TB care providers were in the process to involve in a pilot study that will be using Digital Adherence Technologies (DATs) for adherence to TB treatment and that they were trained already and given the necessary information technology supplies. Among the respondents, $43 \%$ confirmed that they had a favorable working environment to utilize new DHIs in their facilities, and $82 \%$ endorsed sundry opportunities in the health facilities to properly implement digital health interventions in both health centers and public hospitals under the study.

\section{Facility Readiness to Adopt and Implement New DHls}

All study facilities had a dedicated annual budget, a procedure to secure patients' confidentiality and deliver services using
TABLE 3 | Responses of leading questions by the respondents $(n=60)$.

\begin{tabular}{lc}
\hline Leading questions & $\begin{array}{c}\text { Percent } \\
\text { of cases }\end{array}$ \\
\hline Q1 & $29(48.3 \%)$ \\
HCPs heard of DHIs & $51(85 \%)$ \\
HCPs with smartphone & $54(90 \%)$ \\
facillity & \\
Computer access in the healthcare facility & $33(55 \%)$ \\
HCPs having different online training & $7(11.7 \%)$ \\
Experience using EMR & $37(61.7 \%)$ \\
Experience in using any other technologies for & $48(80 \%)$ \\
TB/HIV patients & $45(75 \%)$ \\
The relative advantage of technology & $42(70 \%)$ \\
The simplicity of the technology & $41(68.3 \%)$ \\
Related training that would help to implement & \\
such technology & $16(26.7 \%)$ \\
Adequacy of the training & $26(43.3 \%)$ \\
Favorable environment or infrastructure & $52(86.7 \%)$ \\
Challenges to use DHls in the facility? & $49(81.7 \%)$ \\
Opportunities in the facility to adopt new DHIs? & \\
\hline
\end{tabular}

TABLE 4 | Results from the checklist that assessed facilities' infrastructure and human resource capacity.

\begin{tabular}{|c|c|c|}
\hline Description & Frequency & Percent \\
\hline Personnel (professional IT staffs) & 14 & 100 \\
\hline $\begin{array}{l}\text { Are hardware and software required for } \\
\text { healthcare deliveries readily available? }\end{array}$ & 9 & 64.3 \\
\hline The dedicated annual budget for improving IT & 14 & 100 \\
\hline $\begin{array}{l}\text { Is there any external consultant for installation } \\
\text { and maintenance? }\end{array}$ & 8 & 57.1 \\
\hline $\begin{array}{l}\text { Is there establish inputs from } \\
\text { leadership/management for sustaining the } \\
\text { system? }\end{array}$ & 9 & 64.3 \\
\hline $\begin{array}{l}\text { Any currently delivered services using } \\
\text { technology? }\end{array}$ & 14 & 100 \\
\hline $\begin{array}{l}\text { Any multi-user system (connectivity among } \\
\text { HCPs, laboratory, and others) }\end{array}$ & 1 & 7.1 \\
\hline $\begin{array}{l}\text { Is there a procedure to secure patients' } \\
\text { confidentiality? }\end{array}$ & 14 & 100 \\
\hline $\begin{array}{l}\text { Are governmental and institutional policies } \\
\text { being in place to promote and manage the use } \\
\text { of DHIs? }\end{array}$ & 7 & 50 \\
\hline
\end{tabular}

DHIs, while only one facility implemented a multi-use system (connectivity among HCPs, laboratory, and others) and only three $(21 \%)$ had governmental and institutional DHI policies in place to use and abided by Table 4.

Most of the healthcare providers had intermediate computing and application skills, with $13.3 \%$ having fundamental skills in typing and using mouse and 3.3 having advanced computing and application (Table 5).

Data of the respondents showed that $57 \%$ of facilities had skilled staff on payroll for maintaining computers and other dysfunctions related to technologies. We observed the 
TABLE 5 | Computer skills of HCPs.

\begin{tabular}{lcc}
\hline Computer skill of HCPs & Frequency & Percent \\
\hline Fundamental (typing and using mouse) & 8 & 13.3 \\
Basic computing and application & 16 & 26.7 \\
Intermediate computing and application & 34 & 56.7 \\
Advanced computing and application & 2 & 3.3 \\
Total & $\mathbf{6 0}$ & $\mathbf{1 0 0 . 0}$ \\
\hline
\end{tabular}

TABLE 6 | Checklist on the infrastructure and human resource.

\begin{tabular}{|c|c|c|c|}
\hline Description & & Frequency & Percent \\
\hline \multirow[t]{4}{*}{ Staff with computing skills } & Data entry & 2 & 14.3 \\
\hline & Database mgmt. & 4 & 28.6 \\
\hline & Having all skills & 8 & 57.1 \\
\hline & Total & 14 & 100 \\
\hline $\begin{array}{l}\text { How does your office } \\
\text { manage computing }\end{array}$ & $\begin{array}{l}\text { Outsource whenever } \\
\text { necessary }\end{array}$ & 4 & 28.6 \\
\hline \multirow[t]{3}{*}{ equipment maintenance? } & $\begin{array}{l}\text { Using skills of staff on } \\
\text { payroll }\end{array}$ & 8 & 57.1 \\
\hline & $\begin{array}{l}\text { No Maintenance or } \\
\text { irregular }\end{array}$ & 2 & 14.3 \\
\hline & Total & 14 & 100 \\
\hline \multirow[t]{3}{*}{ Number of computers } & Below 20 & 4 & 28.6 \\
\hline & Above 20 & 10 & 71.4 \\
\hline & Total & 14 & 100 \\
\hline \multirow[t]{3}{*}{ Internet access } & Wi-Fi & 8 & 57.1 \\
\hline & Both Wi-Fi and cable & 6 & 42.9 \\
\hline & Total & 14 & 100 \\
\hline Do you have a functional & NO & 6 & 42.8 \\
\hline Local Area Network for & Yes & 1 & 7.1 \\
\hline \multirow{2}{*}{$\begin{array}{l}\text { interconnectivity for a } \\
\text { general use? }\end{array}$} & plan to establish & 5 & 35.7 \\
\hline & Total & 14 & 100 \\
\hline $\begin{array}{l}\text { How do you ensure security } \\
\text { for computing equipment? }\end{array}$ & $\begin{array}{l}\text { Using the resident } \\
\text { guard/police }\end{array}$ & 14 & 100 \\
\hline
\end{tabular}

average number of computers in each facility during data collection; it was about 20 from the sampled healthcare facilities, with $71 \%$ of the facilities having more than 20 computers. However, for TB and HIV clinics, the average number of computers was not more than 10. Most of the participants used Wi-Fi for service provision, but $43 \%$ used $\mathrm{Wi}-\mathrm{Fi}$ and broadband internet (cable). Thirty-six percent of the facilities had a plan to establish a functional Local Area Network (LAN) for interconnectivity to give better services (Table 6).

\section{DHls Adoption and Implementation}

Cronbach's alpha values for core readiness and organizational cultural readiness were 0.803 and 0.813 , respectively. For value proposition readiness, technological readiness, Regulatory policy readiness, and Operational resource readiness, Cronbach's alpha value was found to be $0.837,0.880,0.905$, and 0.871 ,
TABLE 7 | Facilities readiness $(n=28)$

\begin{tabular}{|c|c|c|c|}
\hline Item & & Frequency & Percent \\
\hline \multicolumn{4}{|l|}{ Core Readiness } \\
\hline The facility conducted prior & No never considered & 12 & 42.9 \\
\hline \multirow[t]{4}{*}{ DHI needs assessment } & $\begin{array}{l}\text { No, but have } \\
\text { considered }\end{array}$ & 7 & 25 \\
\hline & Yes, in progress & 7 & 25 \\
\hline & Yes, nearly completed & 2 & 7.1 \\
\hline & Total & 28 & 100 \\
\hline The facility has a plan to & No never considered & 12 & 42.9 \\
\hline \multirow[t]{4}{*}{ adopt technologies } & $\begin{array}{l}\text { No, but have } \\
\text { considered }\end{array}$ & 6 & 21.4 \\
\hline & Yes, in progress & 8 & 28.6 \\
\hline & Yes, nearly completed & 2 & 7.1 \\
\hline & Total & 28 & 100 \\
\hline \multicolumn{4}{|c|}{ Organizational Cultural Readiness } \\
\hline End users involved in & No never considered & 14 & 50 \\
\hline \multirow[t]{4}{*}{ planning process } & $\begin{array}{l}\text { No, but have } \\
\text { considered }\end{array}$ & 9 & 32.1 \\
\hline & Yes, rarely participated & 1 & 3.6 \\
\hline & Yes, participated & 4 & 14.3 \\
\hline & Total & 28 & 100 \\
\hline The facility identified & Strongly disagree & 1 & 3.6 \\
\hline \multirow[t]{5}{*}{ collaborators. } & Disagree & 4 & 14.3 \\
\hline & Neural & 5 & 17.9 \\
\hline & Agree & 7 & 25 \\
\hline & Strongly agree & 11 & 39.3 \\
\hline & Total & 28 & 100 \\
\hline DHI initiatives supported & Strongly disagree & 5 & 17.9 \\
\hline \multirow[t]{5}{*}{ by management } & Disagree & 4 & 14.3 \\
\hline & Neural & 2 & 9.8 \\
\hline & Agree & 10 & 33 \\
\hline & Strongly agree & 7 & 25 \\
\hline & Total & 28 & 100 \\
\hline \multicolumn{4}{|l|}{ Value proposition readiness } \\
\hline Existing DHls support care & Strongly disagree & 3 & 10.7 \\
\hline \multirow[t]{5}{*}{ delivery mission } & Disagree & 3 & 10.7 \\
\hline & Neural & 3 & 10.7 \\
\hline & Agree & 8 & 28.6 \\
\hline & Strongly agree & 11 & 39.3 \\
\hline & Total & 28 & 100 \\
\hline Patients' safety assurance & Strongly disagree & 0 & 0 \\
\hline \multirow[t]{5}{*}{ is in place } & Disagree & 1 & 3.6 \\
\hline & Neural & 1 & 3.6 \\
\hline & Agree & 9 & 32.1 \\
\hline & Strongly agree & 17 & 60.7 \\
\hline & Total & 28 & 100 \\
\hline \multicolumn{4}{|l|}{ Technological readiness } \\
\hline Practical viability DHIs & No never considered & 7 & 25 \\
\hline \multirow[t]{3}{*}{ checked } & $\begin{array}{l}\text { No, but have } \\
\text { considered }\end{array}$ & 4 & 14.3 \\
\hline & Yes, in progress & 10 & 35.7 \\
\hline & Yes, nearly completed & 4 & 14.3 \\
\hline
\end{tabular}

(Continued) 
TABLE 7 | Continued

\begin{tabular}{|c|c|c|c|}
\hline \multicolumn{2}{|l|}{ Item } & \multirow{2}{*}{$\begin{array}{c}\text { Frequency } \\
3\end{array}$} & \multirow{2}{*}{$\begin{array}{c}\text { Percent } \\
10.7\end{array}$} \\
\hline & Yes, in place & & \\
\hline & Total & 28 & 100 \\
\hline Facility examined the DHIs & No never considered & 10 & 35.7 \\
\hline \multirow[t]{5}{*}{ to be implemented } & $\begin{array}{l}\text { No, but have } \\
\text { considered }\end{array}$ & 5 & 17.9 \\
\hline & Yes, in progress & 5 & 17.9 \\
\hline & Yes, nearly completed & 6 & 21.4 \\
\hline & Yes, in place & 2 & 7.1 \\
\hline & Total & 28 & 100 \\
\hline Guideline on the use of & No never considered & 12 & 42.9 \\
\hline \multirow[t]{5}{*}{ technology available } & $\begin{array}{l}\text { No, but have } \\
\text { considered }\end{array}$ & 5 & 17.9 \\
\hline & $\begin{array}{l}\text { Yes, on process/ in } \\
\text { progress }\end{array}$ & 6 & 21.4 \\
\hline & Yes, nearly completed & 3 & 10.7 \\
\hline & Yes, in place & 2 & 7.1 \\
\hline & Total & 28 & 100 \\
\hline Patient data protection & No never considered & 2 & 7.1 \\
\hline \multirow[t]{5}{*}{ measures are in place } & $\begin{array}{l}\text { No, but have } \\
\text { considered }\end{array}$ & 5 & 17.9 \\
\hline & $\begin{array}{l}\text { Yes, on process/in } \\
\text { progress }\end{array}$ & 8 & 28.6 \\
\hline & Yes, nearly completed & 7 & 25 \\
\hline & Yes, in place & 6 & 21.4 \\
\hline & Total & 28 & 100 \\
\hline \multicolumn{4}{|c|}{ Operational resource readiness } \\
\hline DHI tools for providers and & No never considered & 11 & 39.3 \\
\hline \multirow[t]{5}{*}{ patients identified } & $\begin{array}{l}\text { No, but have } \\
\text { considered }\end{array}$ & 6 & 21.4 \\
\hline & Yes, in progress & 6 & 21.4 \\
\hline & Yes, nearly completed & 3 & 10.7 \\
\hline & Yes, in place & 2 & 7.1 \\
\hline & Total & 28 & 100 \\
\hline There exist good & Strongly disagree & 1 & 3.6 \\
\hline collaboration with IT staffs & Disagree & 2 & 7.1 \\
\hline \multirow[t]{4}{*}{ to implement DHIs } & Neural & 3 & 10.7 \\
\hline & Agree & 9 & 32.1 \\
\hline & Strongly agree & 13 & 46.5 \\
\hline & Total & 28 & 100 \\
\hline \multicolumn{4}{|c|}{ Digital health interventions readiness } \\
\hline Legitimate reasons exist to & Strongly disagree & 1 & 3.6 \\
\hline introduce computer-based & Disagree & 3 & 10.7 \\
\hline \multirow[t]{4}{*}{ system in the TB/HIV unit } & Neutral & 3 & 10.7 \\
\hline & Agree & 10 & 35.7 \\
\hline & strongly Agree & 11 & 39.3 \\
\hline & Total & 28 & 100 \\
\hline Staff need new tools to & Disagree & 1 & 3.6 \\
\hline \multirow[t]{4}{*}{ improve the work } & Neutral & 1 & 3.6 \\
\hline & Agree & 9 & 32.1 \\
\hline & Strongly agree & 17 & 60.7 \\
\hline & Total & 28 & 100 \\
\hline
\end{tabular}

(Continued)
TABLE 7 | Continued

\begin{tabular}{|c|c|c|c|}
\hline Item & & Frequency & Percent \\
\hline Staff in TB/HIV unit will & Disagree & 2 & 7.1 \\
\hline \multirow[t]{4}{*}{ benefit from DHls } & Neutral & 1 & 3.6 \\
\hline & Agree & 16 & 57.1 \\
\hline & Strongly agree & 9 & 32.1 \\
\hline & Total & 28 & 100 \\
\hline DHIs contribute to TB/HIV & Disagree & 2 & 7.1 \\
\hline \multirow[t]{3}{*}{ unit's performance } & Agree & 5 & 17.9 \\
\hline & Strongly agree & 21 & 75 \\
\hline & Total & 28 & 100 \\
\hline The facility is ready to & Strongly disagree & 1 & 3.6 \\
\hline \multirow[t]{5}{*}{ adopt and implement DHIs } & Disagree & 6 & 21.4 \\
\hline & Neutral & 5 & 17.9 \\
\hline & Agree & 9 & 32.1 \\
\hline & Strongly agree & 7 & 25 \\
\hline & Total & 28 & 100 \\
\hline
\end{tabular}

respectively. Such values suggest a strong interrelatedness between measuring items.

Core readiness assessments are meant to guide development efforts by providing benchmarks for comparison and appraising progress. Digital health interventions readiness process based on an objective assessment leads to sound strategies that can offer a path for transfiguring good intentions into planned action that brings real change to people's lives. Using this theme, we had assessed the strategic planning of the facility. Surprisingly, only $32 \%$ of the respondents replied positive responses regarding their need assessment plan on DHIs.

Eighty-two percent of the given health facilities identified other interested health facilities collaborators and stakeholders. Based on this, ICAP and AHF (AIDS Healthcare Fund) were stakeholders in collaborating and facilitating technology utilization. These institutions mainly focused on HIV clinics, provided computers and training for the facilities and HCPs, and $58 \%$ of respondents believed that their management or leadership had supported DHIs initiative.

Sixty-eight percent of the respondents believed that DHIs support the care delivery mission of their respective facilities. Furthermore, 93\% responded that there was a system or process to assure patients' safety and confidentiality. On the other hand, only $39 \%$ of respondents reported that care providers in the facilities were licensed/being licensed/trained to provide care through DHIs. Forty-nine percent of the respondents identified the medical requirements that have met the standards for properly implementing the DHIs in health facilities. Similarly, $46 \%$ confirmed that the facilities had examined the DHIs implemented in the context of workflow in their respective facilities.

There was an absence of guidelines on how to use DHIs in healthcare facilities. Participants blamed and critiqued the lack of any Digital Health policy document, which they understood was hampering the ability of responsible agencies to conduct 
TABLE 8 | Correlations analysis.

\begin{tabular}{|c|c|c|c|c|c|c|c|}
\hline & & $\begin{array}{l}\text { Core } \\
\text { readiness }\end{array}$ & $\begin{array}{l}\text { Operational resource } \\
\text { readiness }\end{array}$ & $\begin{array}{c}\text { Value proposition } \\
\text { readiness }\end{array}$ & $\begin{array}{l}\text { Technological } \\
\text { readiness }\end{array}$ & $\begin{array}{c}\text { Regulatory } \\
\text { policy readiness }\end{array}$ & $\begin{array}{l}\text { Organizational cultural } \\
\text { readiness }\end{array}$ \\
\hline Core readiness & $\begin{array}{l}\text { Pearson } \\
\text { Correlation }\end{array}$ & 1 & $0.550^{\star \star}$ & $0.397^{\star}$ & $0.543^{\star \star}$ & $0.401^{\star}$ & $0.465^{\star}$ \\
\hline $\begin{array}{l}\text { Operational } \\
\text { resource readiness }\end{array}$ & $\begin{array}{l}\text { Pearson } \\
\text { Correlation }\end{array}$ & $0.550^{\star \star}$ & 1 & $0.404^{\star \star}$ & $0.801^{\star \star}$ & $0.538^{\star \star}$ & $0.486^{\star \star}$ \\
\hline $\begin{array}{l}\text { Value proposition } \\
\text { readiness }\end{array}$ & $\begin{array}{l}\text { Pearson } \\
\text { Correlation }\end{array}$ & $0.397^{\star}$ & $0.404^{\star \star}$ & 1 & $0.528^{\star \star}$ & $0.419^{\star}$ & $0.514^{\star \star}$ \\
\hline $\begin{array}{l}\text { Technological } \\
\text { readiness }\end{array}$ & $\begin{array}{l}\text { Pearson } \\
\text { Correlation }\end{array}$ & $0.543^{\star \star}$ & $0.801^{\star \star}$ & $0.528^{\star \star}$ & 1 & $0.630^{\star *}$ & $0.675^{\star *}$ \\
\hline $\begin{array}{l}\text { Regulatory policy } \\
\text { readiness }\end{array}$ & $\begin{array}{l}\text { Pearson } \\
\text { Correlation }\end{array}$ & $0.401^{\star}$ & $0.538^{\star *}$ & $0.419^{\star}$ & $0.630^{\star *}$ & 1 & $0.576^{\star \star}$ \\
\hline $\begin{array}{l}\text { Organizational } \\
\text { cultural readiness }\end{array}$ & $\begin{array}{l}\text { Pearson } \\
\text { Correlation }\end{array}$ & $0.465^{\star}$ & $0.486^{\star \star}$ & $0.514^{\star \star}$ & $0.675^{\star \star}$ & $0.576^{\star \star}$ & 1 \\
\hline
\end{tabular}

${ }^{\star}$ Correlation is significant at the 0.05 level (2-tailed). ${ }^{* *}$ Correlation is significant at the 0.01 level (2-tailed).

and coordinate the activities of various existing silos of digital health-related projects in the facilities. The process of ensuring the availability of relevant tools for DHIs usage for both care providers and care receivers/patients had been identified only by $39 \%$ of the respondents. However, $79 \%$ of respondents confirmed an excellent collaboration with IT staff to implement DHIs in the facility. Overall, most of the respondents believed that more needs to be done for IT to be fully recognized as an essential tool to improve the quality of healthcare delivery. The majority, i.e., $75 \%$, believed legitimate reasons to introduce a computerbased system in their unit, and 93\% needed new tools to improve their workaround. Only $25 \%$ of respondents approved that their respective facility is ready to adopt and implement DHIs to advance healthcare delivery (Table 7).

\section{Correlation Analysis}

A Pearson product-momentum correlation (Pearson $r$ ) was conducted to assess any significant relationship between the composite variables. The Pearson correlation coefficient quantifies the strength of a linear association between two variables and is denoted by $r$. The variables were measured on a ratio scale, which is a prerequisite for using Pearson correlation. All variables demonstrated a positive relationship, i.e., $r$ values were all positive in the range of 0.4 to 0.8 and $p<0.05$ for all, suggesting the contribution of these composite variables toward the assessment of DHIs adoption readiness of selected healthcare facilities, as a dependable construct. The $r$-value, the correlation between Technological Readiness and Operational Resource Readiness was 0.8 . As a result, the correlation between Technological Readiness and Operational Resource Readiness was strongly significant in this analysis (Table 8).

\section{DISCUSSION}

Many have argued that digital health promises enhanced efficiency and quality in healthcare. A facilitating factor for adopting and successfully implementing digital health is the acceptance and readiness of healthcare providers. Based on our findings, all healthcare facilities had professional IT staff and a dedicated annual budget to improve the IT department. All of them currently deliver services using different technologies and had a procedure to protect and keep patients confidentiality. The healthcare facilities used different technologies to simplify their service provision to patients and report and archive data.

Our findings showed that about half of the respondents had limited experience in computing and application skills, and with basic computer skills. Previous studies indicate that healthcare providers with good computer skills or competent enough in using computers were more likely to express their readiness for DHIs implementation and adopt the system in their facilities (32-34). Given the low computer skill of healthcare providers in developing countries, the findings call for a refresher or basic computer skill-based training to be given to healthcare providers before the implementation of DHIs.

In the current study, most care providers mentioned their readiness to use different technologies over the traditional method. They had confirmed the availability of internet access (Wi-Fi and broadband internet), the readiness of generators during light interruption, and accessibility of computers as a good opportunity to implement different technologies currently and in the future. On the contrary, the poor signal strength, lack of maintenance, in some facilities shortage of computers, and above all an absence of adequate spaces were mentioned as the major gaps to effectively implement DHIs. Inadequate training sessions to effectively implement such technologies was also judged a major gap. On the contrary, the willingness of care providers to use technologies and the willingness and potential support of facility leadership were promising enablers of DHIs. The capacity and effective utilization of digital health among healthcare workers depend on their workload, time spent, and documentation length, indicating that the training methods should meet the healthcare providers' learning needs (35).

According to the current study, only one facility established LAN for general use, while the rest 13 facilities use interconnectivity only for HIV units. One-third of the facilities had a plan to establish LAN for general use, with 
potential interconnecting departments and units across the facility. Most of the healthcare facilities have been looking for DHIs that would improve their service delivery and a significant number of healthcare providers agree that DHIs do support the healthcare delivery assignment of their facilities. Key technological categories are also needed to support the implementation process. However, the inadequacy of legislation and policies impeded the implementation of DHIs during the roll-out of large-scale DHIs to navigate the complexities of achieving the milestone and ensuring sustainability (36).

Currently, evidence is insufficiently available on the effectiveness of using DHIs to improve TB and HIV management (37-41). For Ethiopia, where the two diseases are yet the major disease burdens (42-45), studies on DHIs are desperately needed. Be it in hospitals or health centers, implementation of new DHIs in the study facilities require ICT platforms, dedicated and skilled staffing, leadership support, sustainable financing, and stakeholders engagement. The study findings can serve as a baseline for other researchers who would like to do more studies in the field of digital health and can guide policy-makers to intervene in the ongoing implementation of DHIs. Digital health is a new field of study that this study intended to look into. However, more studies are needed that go beyond Addis Ababa to provide a general picture of the finding in Ethiopia. The study assessed the capacity and readiness of healthcare facilities for DHIs against TB and HIV, thus worth extending the assessment for other diseases of national and global importance.

\section{CONCLUSION}

Like many developing countries, there was a modest infrastructure and human resource capacity and readiness of public healthcare facilities in Addis Ababa, Ethiopia, to nurture and strengthen DHIs across the TB and HIV cascades of care. Technological and operational resource readiness,

\section{REFERENCES}

1. Naoum P, Pavi E, Athanasakis K. Economic evaluation of digital health interventions in palliative care: a systematic review of the literature. Front Digit Health. (2021) 3:730755. doi: 10.3389/fdgth.2021.730755

2. Manyazewal T, Woldeamanuel Y, Blumberg HM, Fekadu A, Marconi VC. The potential use of digital health technologies in the African context: a systematic review of evidence from Ethiopia. NPJ Digit Med. (2021) 4:125. doi: 10.1038/s41746-021-00487-4

3. Labrique A, Agarwal S, Tamrat T, Mehl G. WHO Digital Health Guidelines: a milestone for global health. NPJ Digit Med. (2020) 3:120 doi: 10.1038/s41746-020-00330-2

4. World Health Organization. WHO Guideline: Recommendations on Digital Interventions for Health System Strengthening. (2019). Available online at: https://www.who.int/reproductivehealth/publications/digitalinterventions-health-system-strengthening/en/ (accessed August 2, 2020).

5. Azelton KR, Crowley AP, Vence N, Underwood K, Morris G, Kelly J, et al. Digital health coaching for type 2 diabetes: randomized controlled trial of healthy at home. Front Digit Health. (2021) 3:764735. doi: 10.3389/fdgth.2021.764735 including funding and a Well-trained workforce, are essential for successful implementation and use of digital health against the two infectious diseases of global importance in such settings.

\section{DATA AVAILABILITY STATEMENT}

The raw data supporting the conclusions of this article will be made available by the authors, without undue reservation.

\section{ETHICS STATEMENT}

The studies involving human participants were reviewed and approved by the Scientific and Ethics Review Committee of the Center for Innovative Drug Development and Therapeutic Trials for Africa (CDT-Africa), College of Health Sciences, Addis Ababa University, and the Ethics Committee of Addis Ababa Health bureau. The participants (healthcare proviers in TB and HIV departemets) provided written informed consent to participate in this study.

\section{AUTHOR CONTRIBUTIONS}

EG: study conception, data acquisition, synthesis, and first draft. TM and YW: data acquisition and synthesis. TM: resource acquisition. All authors reviewed and approved the final version for publication.

\section{FUNDING}

This study was supported by the Center for Innovative Drug Development and Therapeutic Trials for Africa (CDT-Africa), College of Health Sciences, Addis Ababa University. TM was supported in part by the Fogarty International Center and the National Institute of Allergy and Infectious Diseases of the US National Institutes of Health (D43TW009127).
6. Knight SR, Ng N, Tsanas A, McLean K, Pagliari C, Harrison EM. Mobile devices and wearable technology for measuring patient outcomes after surgery: a systematic review. NPJ Digit Med. (2021) 4:157. doi: 10.1038/s41746-021-00525-1

7. Daniolou S, Rapp A, Haase C, Ruppert A, Wittwer M, Scoccia Pappagallo A, et al. Digital predictors of morbidity, hospitalization, and mortality among older adults: a systematic review and meta-analysis. Front Digit Health. (2021) 2:602093. doi: 10.3389/fdgth.2020.602093

8. Berisha V, Krantsevich C, Hahn PR, Hahn S, Dasarathy G, Turaga P, Liss J. Digital medicine and the curse of dimensionality. NPJ Digit Med. (2021) 4:153. doi: 10.1038/s41746-021-00521-5

9. Lotter W, Diab AR, Haslam B, Kim JG, Grisot G, Wu E, et al. Robust breast cancer detection in mammography and digital breast tomosynthesis using an annotation-efficient deep learning approach. Nat Med. (2021) 27:2449. doi: 10.1038/s41591-020-01174-9

10. Almond H, Long K, Leroux G. Tensions ahead: how do we build feasible digital health systems that are person-centred and usable? Stud Health Technol Inform. (2021) 284:236-8. doi: 10.3233/SHTI210714

11. Wilson D, Sheikh A, Görgens M, Ward K, World Bank. Technology and universal health coverage: examining the role of digital 
health. J Glob Health. (2021) 11:16006. doi: 10.7189/jogh.11. 16006

12. Lyles CR, Wachter RM, Sarkar U. Focusing on digital health equity. JAMA. (2021) 326:1795-6. doi: 10.1001/jama.2021.18459

13. Meyerheim M, Burns-Gebhart A, Mirzaie K, Garani-Papadatos T, Braun $\mathrm{Y}$, Graf N. Challenges and pitfalls for implementing digital health solutions in clinical studies in Europe. Front Digit Health. (2021) 3:730680. doi: 10.3389/fdgth.2021.730680

14. Cordeiro JV. Digital technologies and data science as health enablers: an outline of appealing promises and compelling ethical, legal, and social challenges. Front Med. (2021) 8:647897. doi: 10.3389/fmed.2021. 647897

15. Benis A, Tamburis O, Chronaki C, Moen A. One digital health: a unified framework for future health ecosystems. J Med Internet Res. (2021) 23:e22189. doi: 10.2196/22189

16. Manyazewal T, Woldeamanuel Y, Blumberg HM, Fekadu A, Marconi VC. The fight to end tuberculosis must not be forgotten in the COVID-19 outbreak. Nat Med. (2020) 26:811-2. doi: 10.1038/s41591-020-0 917-1

17. Fauci AS, Lane HC. Four decades of HIV/AIDS-much accomplished, much to do. N Engl J Med. (2020) 383:1-4. doi: 10.1056/NEJMp1916753

18. Burki T. HIV: the next decade. Lancet HIV. (2021) 8:e31921. doi: 10.1016/S2352-3018(21)00105-3

19. Musyoki H, Bhattacharjee P, Sabin K, Ngoksin E, Wheeler T, Dallabetta G. A decade and beyond: learnings from HIV programming with underserved and marginalized key populations in Kenya. J Int AIDS Soc. (2021) 24:e25729. doi: 10.1002/jia2.25729

20. Sharma A, de Rosa M, Singla N, Singh G, Barnwal RP, Pandey A. Tuberculosis: an overview of the immunogenic response, disease progression, and medicinal chemistry efforts in the last decade toward the development of potential drugs for extensively drug-resistant tuberculosis strains. J Med Chem. (2021) 64:4359-5. doi: 10.1021/acs.jmedchem.0c01833

21. Oh S, Trifonov L, Yadav VD, Barry CE 3rd, Boshoff HI. Tuberculosis drug discovery: a decade of hit assessment for defined targets. Front Cell Infect Microbiol. (2021) 11:611304. doi: 10.3389/fcimb.2021.611304

22. Mussie KM, Gradmann C, Yimer SA, Manyazewal T. Pragmatic management of drug-resistant tuberculosis: a qualitative analysis of human resource constraints in a resource-limited country context-Ethiopia. Int $J$ Public Health. (2021) 66:633917. doi: 10.3389/ijph.2021.633917

23. Getachew E, Adebeta T, Gebrie D, Charlie L, Said B, Assefa DG, et al. Pyrosequencing for diagnosis of multidrug and extensively drugresistant tuberculosis: A systemic review and meta-analysis. J Clin Tuberc Other Mycobact Dis. (2021) 24:100254. doi: 10.1016/j.jctube.2021.1 00254

24. Kajogoo VD, Gorret Atim M, Amare D, Geleta M, Muchie Y, Tesfahunei HA, et al. HIV protease inhibitors and insulin sensitivity: a systematic review and meta-analysis of randomized controlled trials. Front Pharmacol. (2021) 12:635089. doi: 10.3389/fphar.2021.635089

25. Chilot D, Woldeamanuel Y, Manyazewal T. Real-time impact of COVID-19 on clinical care and treatment of patients with tuberculosis: a multicenter cross-sectional study in Addis Ababa, Ethiopia. Ann Glob Health. (2021) 87:109. doi: 10.5334/aogh.3481

26. Mussie KM, Gradmann C, Manyazewal T. Bridging the gap between policy and practice: a qualitative analysis of providers' field experiences tinkering with directly observed therapy in patients with drugresistant tuberculosis in Addis Ababa, Ethiopia. BMJ Open. (2020) 10:e035272. doi: 10.1136/bmjopen-2019-035272

27. Yusif S, Hafeez-Baig A, Soar J. An exploratory study of the readiness of public healthcare facilities in developing countries to adopt health information technology (HIT)/e-Health: the case of Ghana. J Healthc Inform Res. (2020) 4:189-214. doi: 10.1007/s41666-020-00070-8

28. Yusif S, Hafeez-Baig A, Soar J. A model for evaluating eHealth preparedness-a case study approach. Transform Gov People Process Policy. (2020) 14:56187. doi: 10.1108/TG-07-2019-0069

29. Godoe P, Johansen T. Understanding adoption of new technologies: technology readiness and technology acceptance as an integrated concept. $J$ Eur Psychol Stud. (2012) 3:38-52. doi: 10.5334/jeps.aq
30. New York State Archives, SUNY Plattsburgh, National Historical Publications and Records. Commission. Technology Infrastructure Checklist. (2018). Available online at: http://www.archives.nysed.gov/common/archives/files/ erecords-suny_technology-infrastructure-checklist.pdf (accessed August 2, 2020).

31. Kabukye JK, de Keizer N, Cornet R. Assessment of organizational readiness to implement an electronic health record system in a lowresource settings cancer hospital: a cross-sectional survey. PLoS One. (2020) 15:e234711. doi: 10.1371/journal.pone.0234711

32. Al-Anezi FM. Evaluating the readiness of mobile technology with respect to eHeath for medication in Saudi Arabia: an integrative perspective. J Multidiscip Healthc. (2021) 14:59-66. doi: 10.2147/JMDH.S287321

33. Biruk S, Yilma T, Andualem M, Tilahun B. Health professionals' readiness to implement electronic medical record system at three hospitals in Ethiopia: a cross sectional study. BMC Med Inform Decis Mak. (2014) 14:115. doi: 10.1186/s12911-014-0115-5

34. Saleh S, Khodor R, Alameddine M, Baroud M. Readiness of healthcare providers for eHealth: the case from primary healthcare centers in Lebanon. BMC Health Serv Res. (2016) 16:644. doi: 10.1186/s12913-016-1896-2

35. Khairat S, Zalla L, Gartland A, Seashore C. Association between proficiency and efficiency in electronic health records among pediatricians at a major academic health system. Front Digit Health. (2021) 3:689646. doi: 10.3389/fdgth.2021.689646

36. LeFevre A, Chamberlain S, Singh NS, Scott K, Menon P, Barron P, et al. Avoiding the road to nowhere: policy insights on scaling up and sustaining digital health. Glob Policy. (2021) 12:110-4. doi: 10.1111/1758-5899.12909

37. Manyazewal T, Woldeamanuel Y, Holland DP, Fekadu A, Blumberg HM, Marconi VC. Electronic pillbox-enabled self-administered therapy versus standard directly observed therapy for tuberculosis medication adherence and treatment outcomes in Ethiopia (SELFTB): protocol for a multicenter randomized controlled trial. Trials. (2020) 21:383. doi: 10.1186/s13063-020-04324-z

38. Kumar K, Ghafur S. What is the clinical effectiveness and cost-effectiveness of using digital health technologies to improve treatment -adherence and outcomes in patients with tuberculosis? Future Healthc J. (2019) 6:389. doi: 10.7861/futurehealth.6-2-s38

39. Ngwatu BK, Nsengiyumva NP, Oxlade O, Mappin-Kasirer B, Nguyen NL, Jaramillo E, et al. The impact of digital health technologies on tuberculosis treatment: a systematic review. Eur Respir J. (2018) 51:1701596. doi: 10.1183/13993003.0159 6-2017

40. Wood BR, Young JD, Abdel-Massih RC, McCurdy L, Vento TJ, Dhanireddy S, et al. Advancing digital health equity: a policy paper of the infectious diseases society of america and the HIV medicine association. Clin Infect Dis. (2021) 72:913-9. doi: 10.1093/cid/ciaa1525

41. Cao B, Bao H, Oppong E, Feng S, Smith KM, Tucker JD, et al. Digital health for sexually transmitted infection and HIV services: a global scoping review. Curr Opin Infect Dis. (2020) 33:44-50. doi: 10.1097/QCO.00000000000 00619

42. Mengesha D, Manyazewal T, Woldeamanuel Y. Five-year trend analysis of tuberculosis in Bahir Dar, Northwest Ethiopia, 2015-2019. Int J Mycobacteriol. (2021) 10:437-41. doi: 10.4103/ijmy.ijmy_181_21

43. Mohammed H, Oljira L, Roba KT, Ngadaya E, Tesfaye D, Manyazewal $\mathrm{T}$, et al. Impact of early chest radiography on delay in pulmonary tuberculosis case notification in Ethiopia. Int J Mycobacteriol. (2021) 10:36472. doi: 10.4103/ijmy.ijmy_216_21

44. Mohammed H, Oljira L, Teji Roba K, Ngadaya E, Mehari R, Manyazewal $\mathrm{T}$, et al. Who to involve and where to start integrating tuberculosis screening into routine healthcare services: positive cough of any duration as the first step for screening tuberculosis in Ethiopia. Risk Manag Healthc Policy. (2021) 14:4749-56. doi: 10.2147/RMHP.S3 37392

45. Mussie KM, Yimer SA, Manyazewal T, Gradmann C. Exploring local realities: perceptions and experiences of healthcare workers on the management and control of drug-resistant tuberculosis in Addis Ababa, Ethiopia. PLoS One. (2019) 14:e0224277. doi: 10.1371/journal.pone.02 24277 
Author Disclaimer: The content is solely the authors' responsibility and does not necessarily represent the official views of the CDT-Africa or the National Institutes of Health.

Conflict of Interest: The authors declare that the research was conducted in the absence of any commercial or financial relationships that could be construed as a potential conflict of interest.

Publisher's Note: All claims expressed in this article are solely those of the authors and do not necessarily represent those of their affiliated organizations, or those of the publisher, the editors and the reviewers.
Any product that may be evaluated in this article, or claim that may be made by its manufacturer, is not guaranteed or endorsed by the publisher.

Copyright (๑ 2022 Getachew, Woldeamanuel and Manyazewal. This is an openaccess article distributed under the terms of the Creative Commons Attribution License (CC BY). The use, distribution or reproduction in other forums is permitted, provided the original author(s) and the copyright owner(s) are credited and that the original publication in this journal is cited, in accordance with accepted academic practice. No use, distribution or reproduction is permitted which does not comply with these terms. 